Cirurgia

\section{CONSIDERAÇÕES SOBRE GRAVIDEZ APÓS CIRURGIA BARIÁTRICA: EVIDÊNCIAS ATUAIS E RECOMENDAÇÖES}

Os autores desse artigo de revisão abordam os seguintes aspectos em mulheres submetidas à cirurgia bariátrica: o aumento da fertilidade pós-operatória, a suplementação nutricional, segurança da gravidez após cirurgia bariátrica e efeito da gravidez sobre a perda de peso pós-operatória. As mulheres em idade reprodutiva correspondem a quase $50 \%$ dos pacientes submetidos à cirurgia bariátrica. As cirurgias disabsortivas, restritivas ou tipo diversão pancreática podem levar a deficiências de ferro, cálcio, tiamina e a má absorção de gorduras, vitaminas lipossolúveis e vitamina B 2 .

Devido a essas deficiências, em teoria, tanto a mãe como o feto estão sujeitos a doenças como parto prematuro, baixo peso do feto ao nascer, osteomalacia materna, retardo mental do feto e defeitos do tubo neural. As mães submetidas a cirurgia de Capella podem apresentar obstrução intestinal devido à compressão intestinal causada pelo útero em crescimento. Foram descritos na literatura nove casos de morte por obstrução intestinal por esta causa. Sheiner et al. estudaram 298 partos em pacientes anteriormente submetidas à cirurgia bariátrica em Israel, não sendo descritas má formação ou qualquer outra anormalidade nessas crianças ao nascimento. Outros autores recomendam que a gravidez ocorra pelo menos um ano após a cirurgia, pois esse é o período de maior perda de peso e, portanto, a gravidez pode ser prejudicial à mãe e ao feto.

Em conclusão, os autores sugerem as seguintes recomendações a mulheres em idade reprodutiva submetidas à cirurgia bariátrica:

a) promover algum método contraceptivo nos primeiros 12 a 18 meses após a cirurgia;

b) acompanhamento nutricional e suplementação vitamínica no pós-operatório;

c) suplementação vitamínica diária durante a gravidez, além da suplementação de ferro, cálcio e proteínas (60 g diárias);

d) ficar atento ao risco de obstrução intestinal na mãe durante a gestação, sendo que a tomografia pode ser útil no diagnóstico;

e) acompanhar rigorosamente as alterações do peso da paciente tanto durante a gravidez como no pós-parto;

f) esclarecer os obstetras sobre o alto risco da gravidez nessas pacientes submetidas à cirurgia bariátrica

\section{Comentário}

A gravidez de pacientes submetidas à cirurgia bariátrica preocupa muito o médico que as acompanha. As recomendações sugeridas pelos autores nos parecem muito úteis e de bom senso e devem ser aplicadas nessas pacientes. Achamos, no entanto, que o assunto está longe de ser encerrado, havendo a necessidade de mais estudos a respeito. Enquanto isso não acontece, recomendamos que todas as mulheres jovens que tenham a pretensão de se submeter à cirurgia bariátrica devam ser alertadas sobre os riscos da gravidez no pós-operatório, tanto no que se refere à mãe quanto ao feto.

ELIAS JiRJoss ILIAS
Referência

Beard $J H$, Bell RL, Duffy AJ. Reproductive considerations and pregnancy after bariatric surgery: current evidence and recommendations. Obes Surg. 2008; 1 8: 1023-7.

\section{Gastraenteralagia}

\section{USO DE TESTES NÄO-INVASIVOS NA AVALIAÇÄO DA HIPERTENSÄO PORTAL}

As varizes de esôfago são resultantes da hipertensão portal e incidem em cerca de 50\% dos pacientes com cirrose hepática. O risco de sangramento é de cerca de 30\% no primeiro ano após a detecção das varizes. A mortalidade após o primeiro episódio de hemorragia digestiva é da ordem de $30 \%$. Sendo assim, o rastreamento de varizes esofagianas e de sinais da cor vermelha pode prevenir a hemorragia através da adoção de profilaxia primária. A profilaxia antes do primeiro sangramento pode ser medicamentosa, pelo uso de betabloqueadores e nitratos; ou endoscópica, pelo emprego da ligadura elástica. Têm sido estudadas formas não-invasivas de detecção de hipertensão portal sem a necessidade de realizar endoscopia digestiva. Os parâmetros não-invasivos mais freqüentemente explorados são o tamanho do baço e a contagem de plaquetas. A trombocitopenia inferior a $88 \mathrm{mil} / \mathrm{mm}^{3}$, associada à esplenomegalia, indica maior risco de sangramento digestivo varicoso. A razão entre contagem de plaquetas/tamanho do baço superior ao valor de 909 indica ausência de varizes esofagianas, portanto dispensa o paciente da profilaxia medicamentosa.

\section{Comentário}

A razão entre contagem de plaquetas/tamanho de baço apresenta valor preditivo negativo de $100 \%$ e valor preditivo positivo de 83\%, no entanto não traz correlação com o tamanho das varizes esofagianas. Na tentativa de aumentar o poder discriminativo dos testes não-invasivos, buscou-se a determinação de outro parâmetro que se correlacione fortemente com a presença e o tamanho das varizes. Este parâmetro é a razão entre o tamanho do lobo direito/nível sérico de albumina, sendo que o valor de corte é 4.425 , alcançando uma sensibilidade de $83,1 \%$ e especificidade de 73,9\%. A obtenção de testes de maior acurácia pode evitar a realização de exames invasivos e de maior custo em pacientes com varizes de maior calibre e com risco de sangramento, além de ajudar na seleção de pacientes que necessitam de endoscopias mais freqüentes. A partir da informação do teste não-invasivo pode-se iniciar a profilaxia primária. A endoscopia digestiva poderia ser reservada à terapêutica nos casos de intolerância medicamentosa e necessidade de ligadura elástica profilática. É, porém, improvável que os testes não-invasivos venham a excluir os pacientes de uma endoscopia digestiva inicial.

\section{Gustavo Pignaton de Freitas}

Referência

Sen S, Griffiths WJ. Non-invasive prediction of oesophageal varices in cirrhosis. World J Gastroenterol. 2008; | 4( I 5):2454-5. 